\title{
Effectiveness of Techniques to Develop and Assess the Teamwork Skills of First-Year Engineering Students
}

\section{Dr. Jean Carlos Batista Abreu, Elizabethtown College}

Dr. Batista is an Assistant Professor of Engineering at Elizabethtown College. He earned his Ph.D. and M.S.E. at the Johns Hopkins University, M.S. at the University of Puerto Rico, and B.S.E. at the Pontificia Universidad Católica Madre y Maestra, all in Civil Engineering.

\section{Dr. Brenda Read-Daily, Elizabethtown College}

Dr. Brenda Read-Daily is an Associate Professor of Engineering at Elizabethtown College in Pennsylvania and a licensed professional engineer. She holds a BS in Civil Engineering from Bradley University, and a $\mathrm{MS}$ and $\mathrm{PhD}$ in Environmental Engineering from the University of Notre Dame. 


\title{
Effectiveness of Techniques to Develop and Assess the Teamwork Skills of First-Year Engineering Students
}

\begin{abstract}
This Complete Evidence-Based Practice paper explores the advantages and impact of techniques used to improve teamwork in an introduction to engineering course. The main goal of this study is to evaluate the effectiveness of methods used to develop and assess teamwork skills based on student performance and perception. This study integrates, interprets and contrasts quantitative and qualitative data obtained through a mixed-methods approach. Results indicate that students' attitudes toward teamwork and their perceptions of their own teamwork skills improved over the semester.
\end{abstract}

\section{Introduction}

Teamwork is vital to engineers' professional lives. Passow 2012 surveyed over 4000 practicing engineers representing eleven different disciplines asking them to evaluate the importance of the different ABET competencies in their careers [1]. Teamwork (ABET Outcome 5, formally ABET Outcome D) received the highest rating.

Considering its importance to the field, team-based assignments, particularly semesterlong design projects, are commonly employed in engineering curricula. While teamwork can be a rewarding experience, it can also be a source of anxiety and stress. Students may enjoy working collaboratively with others on a challenging goal. However, others often express frustration when team communication breaks down, team members manage time differently, or when group members' contributions are inequitable [2].

Previous research in engineering education has examined best practices in engineering and assessment strategies. These practices include instructor-formed teams that do not isolate underrepresented groups, establishing team policies through team contracts or operation agreements, and providing accountability through peer-evaluations [3]. Google's research on teams revealed that the highest functioning teams provide psychological safety where team members trust one another enough to share their concerns without fear of retribution [4].

While best practices in teamwork are widely reported, fewer studies have evaluated students' attitudes and perceptions of these efforts to improve team dynamics. Researchers studied students' attitudes toward teamwork in a project-based first-year introductory engineering course [2]. Others examined students' perceptions of teamwork supports evaluating the effectiveness of interventions such as ice breakers, operating agreements, peer and self-evaluations, peer mentoring, Gantt charts, and reflections [5]. 
This study builds upon the literature by incorporating the Gallup StrengthsFinder Inventory and conflict resolution training while also addressing previously studied methods like team contracts, peer evaluations, and reflections. The Gallup StrengthsFinder Inventory has been previously implemented in engineering classrooms [6], [7], [8]. However, this study is the first to look at students' perceptions of how this tool impacts their teamwork. Also, this paper addresses how students' perceptions and attitudes concerning teamwork change as a result of working on a semester-long project with the same team.

\section{Context}

The activities described in this paper were implemented during one semester of an Introduction to Engineering course at Elizabethtown College. The department offers ABET-accredited BS degrees in engineering and computer engineering. Both majors are required to take Introduction to Engineering. The course was comprised of 46 students in two sections, 22 in Section A, and 26 in Section B, with 37 male (80.4\%) and nine female (19.6\%) students. The vast majority were first-year intended engineering or computer engineering majors (93.5\%). Two students were high school dual enrollment students $(4.3 \%)$, and one was a non-major student taking the course as part of a technical design minor $(2.2 \%)$.

Team taught by two instructors, the course meets twice a week for 100 minutes with the instructors alternating days when they are in class. Students spend an additional 80 minutes session a week in a fabrication lab associated with the course. The class is a project and team-based studio course where lectures are minimized, and students work on assignments projects together for the majority of class time. Students work on teams of four to five on a semester-long design project where they build and program a temperature sensor which they later use to collect data on campus to assess the window's energy efficiency. Given the heavy focus on teamwork, approximately $50 \%$ of the overall grade specifically comes from team assignments. Therefore, a students' academic success in the course is largely dependent on their team's performance.

\section{Methods}

This study aimed to evaluate the effectiveness of techniques used to develop and assess teamwork skills based on student performance and perception. A mixed-methods approach was used to integrate, interpret and contrast quantitative and qualitative data. This section describes the methods used to gather such data.

\section{Implementation of the Gallup StrengthsFinder ${ }^{\circledR}$ Inventory}

The Gallup StrengthsFinder ${ }^{\circledR}$ Inventory is used to identify an individual's top-five Strengths from the 34 themes. Each of the 34 Strengths bin into one of four domains: Strategic Thinking, Executing, Relationship Building, and Influencing. These Strengths are natural tendencies or preferences that, when leveraged, result in increased productivity and a stronger sense of personal fulfillment [9]. All students completed the 
inventory outside of class. The inventory takes approximately 30 minutes to complete with the results provided immediately. The inventory provides the user with their top five Strengths.

During one class period, students worked with the institution's Strengths Coach to learn about their unique set of strengths and how they can leverage those strengths as future engineers. Students also worked in their project teams to learn about one another's strengths and how they can best communicate and operate with one another.

\section{CATME TeamMaker}

The CATME TeamMaker tool is used to sort students into teams [10]. The software allows the instructors to weight the questions and provides an optimization that considers each of the factors. Students were sorted based on gender, strengths domains, schedule, residential or commuter, programming skills, and CAD skills (Appendix A). The gender, strengths domains, programming skills, and CAD skills were selected to sort dissimilar so that a diversity of strengths and skills were represented on each time while ensuring that female students were not isolated on teams. Given that the class sizes were twenty-six students or less with low racial diversity, the faculty manually adjusted teams to ensure underrepresented students were not isolated.

\section{Instruction on Conflict Resolution}

Right after teams were formed, students participated in a class discussion on conflict resolution. The main objectives of the discussion were to identify root causes of conflict, identify potential sources of escalation, and describe and compare conflict resolution techniques based on the Thomas-Kilmann model [11].

\section{Team Contract}

As one of their first assignments as a group, teams worked to develop a team contract [12] assigning roles and responsibilities considering one another's strengths. They also determined how they would communicate with one another and how they would work through conflict as a team.

\section{CATME Peer Evaluations}

Students conducted peer evaluations using CATME three times throughout the semester at weeks 5, 9, and 14. The CATME Peer Evaluation software allows students to provide anonymous feedback to the instructors on team dynamics [13]. The first evaluation was formative, and the second two were summative. When the results indicated problems on a team, the instructors met with the group or used an "Early Warning" system to notify the students they need to improve their teamwork contributions or be at risk for a deduction in their teamwork grade for the course. 


\section{Reflection}

At the end of the semester following the students' submission of their final project report, students reflected on their experience of working on a team. See Appendix B for the reflection prompt. These reflections provided qualitative data on students' perceptions of their experience of working on a team.

\section{Survey on Perceptions of Interventions}

Two similar surveys were conducted (Appendix C). The surveys asked students to rate their perceptions of teamwork and their own skills in communicating, managing, delegating, and resolving conflict. The surveys were intentionally concise. The average initial and final survey completion times were 1.5 and 4.0 minutes, respectively. Therefore, survey fatigue was not a major concern in this study.

\section{Results and Discussion}

Quantitative and qualitative data were gathered to understand students' perceptions of their individual skills and how those perceptions evolved as students gained knowledge and experience. This section summarizes and discusses the findings.

\section{Quantitative Results}

Quantitative data was gathered through surveys and CATME peer evaluations. The surveys asked students to rate their self-perception on skills in:

- Q1: effectively communicating

- Q2: resolving conflicts

- Q3: managing a team (e.g., establishing goals, organizing, and planning tasks)

- Q4: enjoying teamwork (e.g., building rapport and fostering inclusiveness)

- Q5: delegating tasks and trusting others

The rating scale included five options: "strongly disagree," "disagree," "neutral," "agree," and "strongly agree". The first three were considered "low level," and the last two were considered "high level" of perceived skill.

Before embracing the team project, $26 \%$ of the responses fell into the low level of perceived skill; however, by the end of the course, only $9 \%$ of the responses fell in this category (Figure 1). Therefore, on average, students' perceptions experienced a positive change.

About $35 \%$ of the students appeared not as competent as they initially thought. In total, $24 \%$ of the students changed their perception of skills from a high to a low level (mostly from "agree" to "neutral"), in at least one response; however, many rated themselves high in the initial survey. Only two students (4.3\%) changed one of their responses from "agree" to "disagree," which occurred in questions related to their ability to enjoy teamwork and trust others. These two students experienced team conflict. 


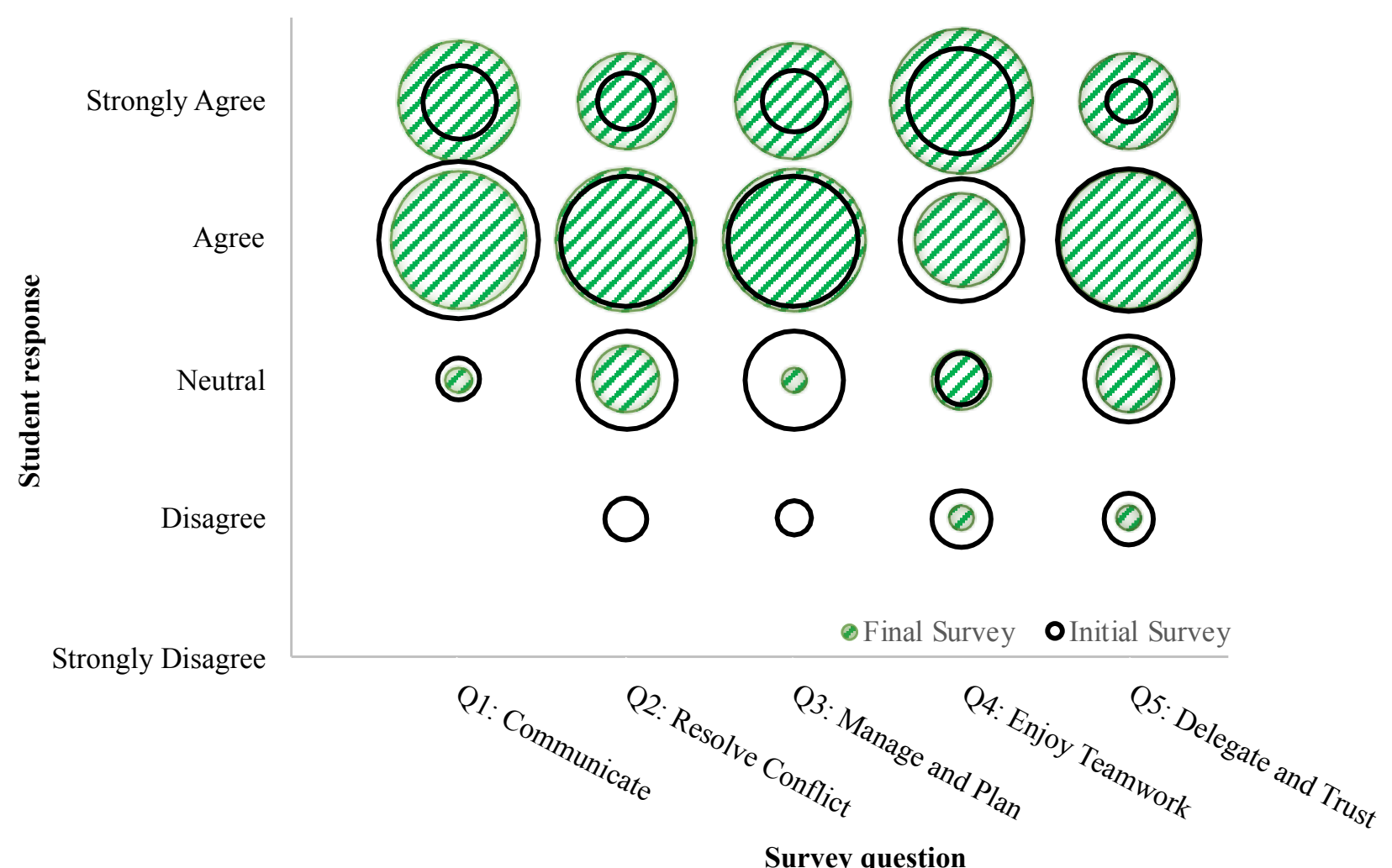

Figure 1: Student responses on their individual perceptions before starting and after completing the team project (Q1-Q5 refer to survey questions listed in Appendix C)

By the end of the course, $76 \%$ of the students positively changed their perception (e.g. from "agree" to "strongly agree") concerning one or more skills. About $63 \%$ of the students perceived significant improvement in their teamwork skills; those students changed their responses in at least one question from low to high levels (e.g. from "disagree" to "strongly agree").

Significant improvement on conflict resolution, project management skills and the ability to delegate and trust others were notorious (Figure 2). However, not all the skills showed positive change in the first half of the semester, according to CATME peer evaluations. Figure 3 indicates that, with respect to initial responses given on week 4, students rated their peers lower on "contributing" to the team's work, "interacting" with teammates, and "expecting quality" by week 9 . After completing the project, all peerassigned CATME scores were higher than before.

Noticeably, most of the students who received the highest final scores in this course (i.e. top $20 \%$ ) did not answer "strongly agree" to any of the questions in the initial survey. However, most of them answered "strongly agree" to at least one of the questions in the final survey, indicating that they perceived progress in their teamwork skills. In contrast, most of the students who received the lowest final scores in this course answered "strongly agree" to at least one of the questions in the initial and final surveys. 


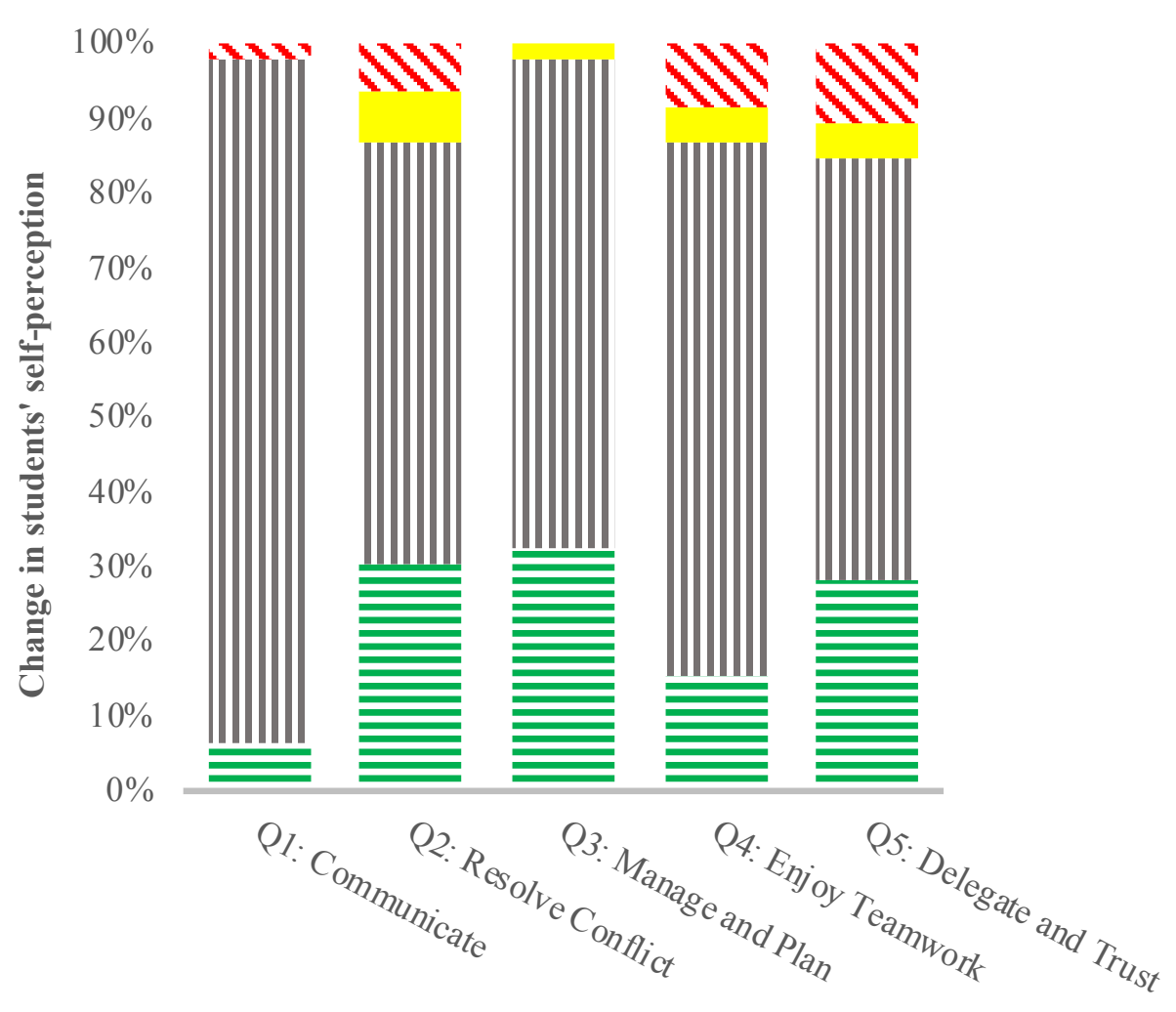

Survey question

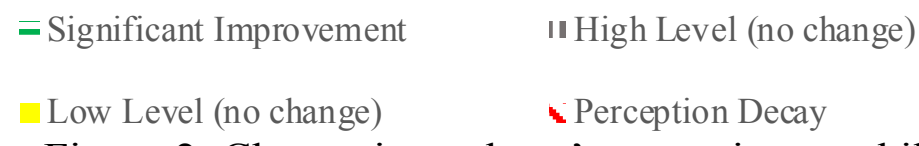

Figure 2: Change in students' perception on skills

Other questions were included in the surveys to better characterize the group of students taking the course. In summary, it was observed that most of them like working in teams ( $80 \%$ and $87 \%$ according to the initial and final surveys, respectively). About $43 \%$ of the students prefer taking charge of their teams, and most of those indicated that they would step in to complete tasks assigned to less productive teammates. Also, results indicate that the percentage of students who find conflict stressful and destructive decreased from $52 \%$ to $22 \%$ by the end of the course.

Final survey results show that the most effective technique to develop teamwork relates "Project Management," based on students' perception. This technique involves requiring students to set clear goals for the team, assign roles and responsibilities, delegate tasks, and maintain a distributed workload. In most workdays, students were asked or encouraged to establish a clear plan before undertaking assignments, and they found this strategy to be very effective.

Most students perceived that identifying their own skills (before working with others) and becoming members of diverse teams was advantageous (Figure 4). In their team contracts all teams explained that they identified leadership, and assigned roles and responsibilities based on their individual strengths and personal interests. 


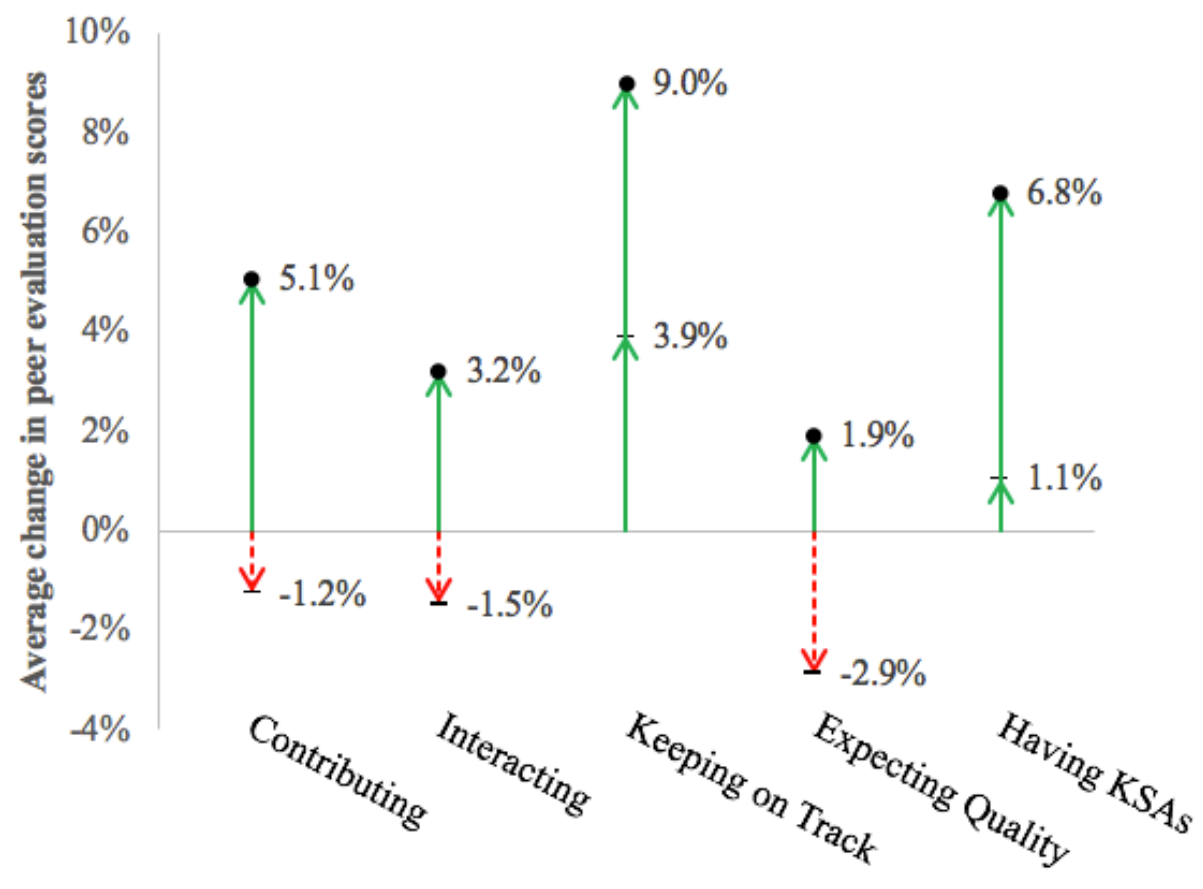

CATME rating category

- Mid-Semester

- End-of-Semester

Figure 3: Changes in CATME peer evaluation scores at week 9 (Mid-Semester) and week 14 (End-of-Semester) with respect to scores given at week 4

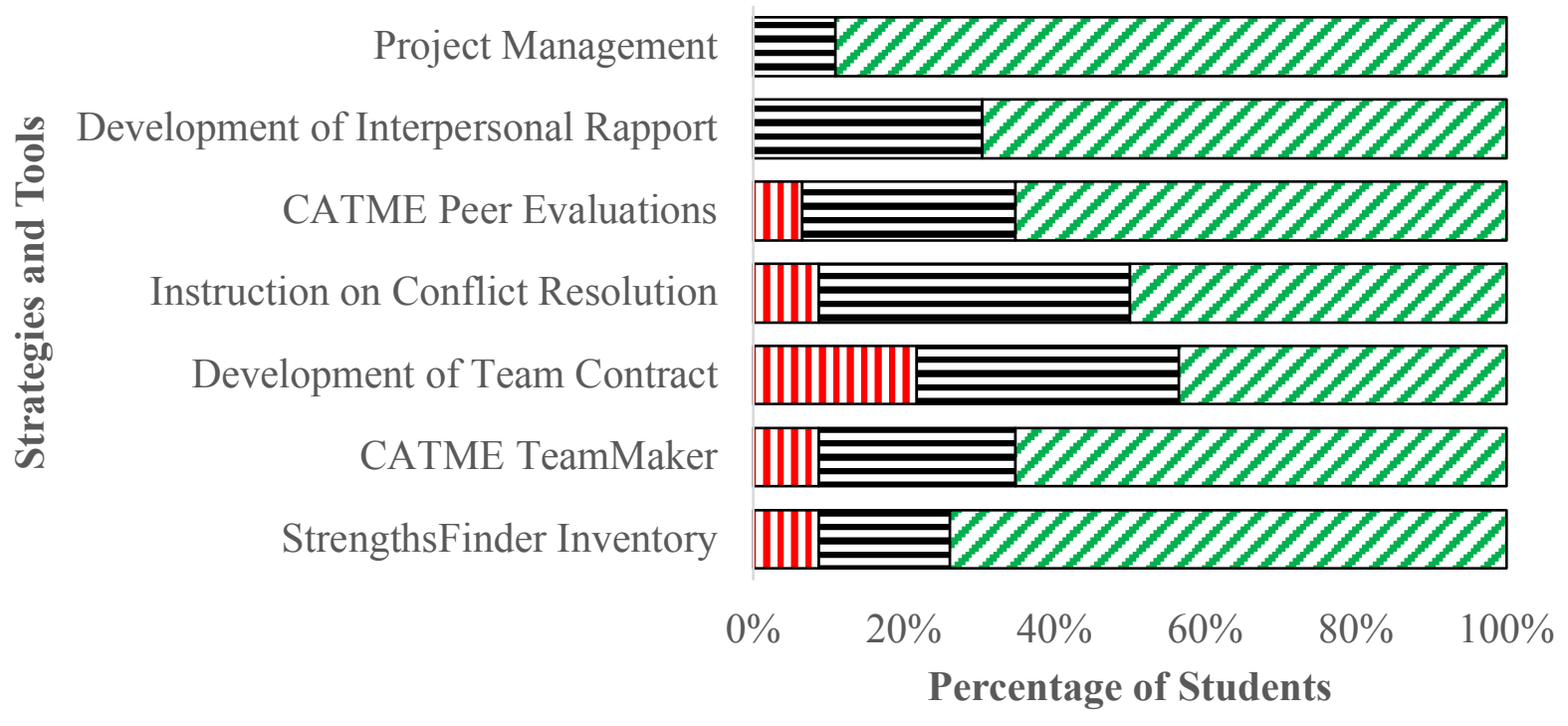

@Very low/Low घNeutral @High/Very high

Figure 4: Perceived effectiveness of implemented strategies and tools 
Half of the students highlighted the effectiveness of conflict resolution instruction. In their team contracts, many teams highlighted conflict prevention and their willingness to compromise; however, most students report not facing major conflicts throughout the course. About $65 \%$ of the students concluded that CATME peer evaluations were effective tools to assess teamwork and provide feedback.

According to students' perception, the development of a team contact was the least effective strategy from the ones listed in the survey; however, $43 \%$ of the students found the team contract to be an important tool for their team's success, and many mentioned its relevance and impact in final reflections.

\section{Qualitative Results}

Qualitative results gathered from student reflections from the end of the semester were coded to determine students' perceptions their teamwork skills. Forty-one of students completed the reflection. Twenty-nine of the forty-one students $(70.7 \%)$ described how their teamwork skills improved throughout the semester using such words as improve, strengthen, growth, develop, or evolve. Some students mentioned that "at the beginning of the semester it was hard to work on group projects and not just by [themselves]. " In their final reflections, the vast majority of students expressed that their "teamwork skills evolved greatly" in this course. All the strategies and tools applied to foster the development of teamwork skills were highlighted in multiple reflections. The development of self-awareness and gaining knowledge of personal skills was a common theme. Students emphasized the importance of understanding that "each person has unique abilities" and the benefits of utilizing such abilities to "get the work done efficiently," even when students "don't really enjoy working in groups." Some mentioned that knowing "how to use [their] strengths" help them "contribute, share ideas and be more confident" when working with others. Specifically, the CATME TeamMaker tool was found "really helpful to form great teams".

Some students commented that "knowing each other's strengths does not guarantee quality work." $36.6 \%$ of the students noted the importance of communication. One student writes, "listening and communicating effectively is essential" to have a successful team. 5 students reported that their teams positively evolved, with some acknowledging "conflicts at first." Examples of conflicts mostly related to scheduling out-of-class team meetings for which students tended to "compromise." One student mentioned that instructions on conflict resolution "can be very useful in the future."

Another common theme was the development of project management skills $(28.6 \%)$ with respect to leadership, delegating tasks, organizing, and trusting teammates. Students felt empowered to "organize the group, get everything turned in on schedule and finish assignments with quality". Others related team management with the ability to "rely on and trust others when working in groups" Delegating tasks was seen as a positive strategy to "ensure that everyone had a fair role in the assignment." 
One student stressed the use of the "team contract to help mitigate any injustice between people in the team, which helped a lot." Another student found that the "team contract really helped the team work well together because... [they] had to give out roles to different members of the team." The team contract also "helped to evenly split work up among members of the group based on personal strengths. '

Building interpersonal rapport was directly tied to having an inclusive environment, being successful, and enjoying teamwork with $14.6 \%$ of students describing the importance of getting along, becoming friends, or forming bonds with their teammates. One student said it is "important to get along with [teammates] for the betterment of the project." Other students mentioned that teammates "became good friends" and "formed a great bond with each other." In a subsequent course, many students sat with members of their previous teams hoping and, in some cases, explicitly soliciting to continue working together.

Regarding peer assessments, one student wrote: "having to evaluate each other on CATME helped our skill evolution. Evaluating my groupmates made me think about persevering in my own regard, using my skills more beneficially for the team". Other student said "the peer reviews are also a spectacular tool. These reviews allow students who feel as though they are doing too much to tell the professor and acknowledge the feedback."

Other comments:

- "The course gave us a platform where we could work as a team and this helps us get out of our comfort zones and consider our teammates when doing an assignment."

- "My teamwork skills have improved throughout this course. I believe that teamwork is a key for success in the engineering business and without it you won't get too far."

- "The final project was the ultimate test for our teamwork and collective designs, and I feel that our team worked not only productively, but in perfect unison."

- "This project contributed to developing teamwork skills at least as much as it contributed to gaining new information."

- "It's not like other math-based classes with you are given an equation and you must find the answer. In this class you must find the equation to get the answer and the equation starts with team work(sic)."

\section{Conclusions}

This study found that students' attitudes toward teamwork and their perceptions of their own teamwork skills improved over the semester. In particular, survey data revealed that students felt that they most improved in the categories of resolving conflict, project management, delegating tasks, and trusting others. With the CATME Peer Evaluation Results, the students' ratings were strong at Week 5 but dipped some at Week 9. This result is likely due to the students completing more challenging tasks during a more stressful time of the semester when deadlines were looming. Later at Week 14, after the 
project was complete and their final report submitted, students scored their team members more favorably indicating that they improved their skills throughout the course and successfully navigated earlier challenges. In their reflections, students frequently cited the team contract and CATME Peer Evaluation tools as important for ensuring peer-to-peer accountability, good project management, and equitable distribution of tasks. In some areas such as communication, students felt they had strong skills coming into the project, and they reported no change by the end of the project. Survey data and reflections revealed that most students viewed the CATME StrengthsFinder tool as beneficial to their teamwork. Given that student perceptions were generally positive toward the different interventions, the instructors will continue implementing these practices but will examine ways to clarify the utility or improve upon the techniques with lower ratings. 


\section{References}

[1] H.J. Passow, "Which ABET Competencies Do Engineering Graduates Find Most Important in their Work?," Journal of Engineering Education, vol. 101, pp. 95-118. 2012.

[2] L. K., Alford, R. Fowler, and S. Sheffield. "Evolution of Student Attitudes Toward Teamwork in a Project-based, Team-based First-Year Introductory Engineering Course," in ASEE Annual Conference Proceedings, Indianapolis, Indiana, 2014.

[3] B. Oakley, R. Felder, R. Brent, and I. Elhajj, "Turning Student Groups into Effective Teams," Journal of Student Centered Learning, vol 2-1, pp 9-34. 2004.

[4] C. Duhigg. "What Google learned from its quest to build the perfect team," The New York Times Magazine, p. 20, Feb 25, 2016. [Online]. Available: New York Times, https://www.nytimes.com.[Accessed Feb 3, 2020].

[5] R. Fowler, L. K. Alford, J.A. Coller, S. Sheffield, and M. P. Su, "Student Perceptions of Teamwork Support", in ASEE Annual Conference Proceedings, Tampa, Florida, 2019.

[6] B. Read-Daily, K. M. DeGoede, K. M., and S. L. Zimmerman, "Gallup StrengthsFinder in Engineering", in ASEE Annual Conference Proceedings, Salt Lake City, Utah, 2018.

[7] S. Lorimer and J. A. Davis, "Using Strengths of First-Year Engineering Students to Enhance Teaching," in ASEE Annual Conference Proceedings, Seattle,WA, 2015.

[8] S. Lorimer and E. Elford, "StrengthsQuest for Engineers," in ASEE Annual Conference Proceedings, San Antonio, Texas, 2012.

[9] T. Rath, StrengthsFinder 2.0, New York: Gallup Press, 2007.

[10] R. A. Layton, M. L. Loughry, M. W. Ohland, and G. D. Ricco, "Design and validation of a web-based system for assigning members to teams using instructorspecified criteria," Advances in Engineering Education, vol.2-1, pp. 1-28. 2010.

[11] Thomas, Kenneth \& Kilmann, Ralph. "Thomas-Kilmann conflict MODE instrument." 10.1037/t02326-000. 1976.

[12] Transferable Integrated Design Engineering Education, Teamwork Assessment for Capstone Engineering Design, www.tidee.org [no longer available], 2008.

[13]M. W. Ohland, M.L. Loughry, D. J. Woehr, C.J. Finelli, L.G. Bullard, R. M. Felder, R. A. Layton, H.R. Pomeranz, and D. G. Schmucker, "The Comprehensive Assessment of Team Member Effectiveness: Development of a Behaviorally Anchored Rating Scale for Self and Peer Evaluation." Academy of Management Learning \& Education, vol. 11-4, pp. 609-630. 2012. 


\section{Appendix A: Questions and Prompts Used for Forming Teams in CATME}

Q1: Check the domains in which you have strengths:

Executing: Achiever, Belief, Consistency, Deliberative, Discipline, Focus, Responsibility, Restorative Influencing: Activator, Command, Communication, Competition, Maximizer, Self-Assurance, Significance, Woo

Relationship Building: Adaptability, Connectedness, Developer, Empathy, Harmony, Includer, Individualization, Positivity, Relator

Strategic Thinking: Analytical, Context, Futuristic, Ideation, Input, Intellection, Learner, Strategic

Q2: Please indicate the times that you are in class, at work, or practice and are busy and unavailable for group work.

Q3: What is your gender?

Q4: Select your top 5 strengths.

Q5: How much experience do you have with programming?

Q6: How much experience do you have with Computer Aided Design (CAD)?

Q7: Are you a high school or commuter student? 


\section{Appendix B: Reflection Prompt}

\section{EGR 191 - Introduction to Engineering I}

Project Reflection

December 4-5, 2019

This semester, your team built a temperature sensor to assess the energy-efficiency of windows at Elizabethtown College, and subsequently generated recommendations to reduce the cost of energy. In this final activity, you will reflect on the project from diverse perspectives, and think more broadly about engineering projects and teamwork.

\section{Assignment}

Write a short reflective essay to address the following questions and topics.

1. You participated in an interdisciplinary project that involved knowledge, methods and technology to solve a problem directly related to several engineering fields, such as civil, computer, electrical, environmental, and mechanical engineering. Explain which specific aspects and goals of the project pertain to those disciplines. What are the advantages and disadvantages of having a broad engineering education when participating in the development of interdisciplinary projects?

2. The development of teamwork skills was one of the main objectives of EGR 191. Explain how your teamwork skills evolved this semester. How did the course contribute to the understanding and development of your teamwork skills? Discuss specific activities/techniques/instructions/tools.

3. After completing the EGR 191 project and many other team assignments, what advice would you offer to first year engineering students coming to Elizabethtown College next year? How could they be successful when completing team assignments?

4. Provide at least two creative ideas on how to improve/restructure/change the EGR 191 project: "Energy-Efficiency Assessment of Windows Using Temperature Sensors". Explain your ideas and discuss clear examples showing how to implement them in the near future.

Format guidelines

Use Times New Roman, size 11, single spacing, justify text, single column. Aim for 1 page, and do not exceed two pages. 


\section{Appendix C: Survey on Perceptions of Interventions}

Answer the following questions considering that you will be working on a semesterlong project with the same teammates that amounts to roughly $50 \%$ of grade in the course (or after completing a semester-long team project in EGR 191 - Introduction to Engineering I). Select "strongly agree", "agree", "neutral”, "disagree" or "strongly disagree".

Q1: When working on a team project (or During my experience in EGR 191), I was comfortable with my ability to effectively communicate with my teammates. For example, I typically applied effective strategies to better communicate with others based on their preferred communication style.

Q2: If conflict arises in my team (or During my experience in EGR 191), I felt equipped to resolve conflicts by applying systematic conflict resolution techniques.

Q3; (During my experience in EGR 191) I am/was confident in my ability to organize a team, establish goals, and plan tasks to meet objectives with a quality level that satisfies everyone.

Q4: (During my experience in EGR 191,) I like/liked working in teams.

Q5: (During my experience in EGR 191,) I am/was comfortable delegating tasks to others and trusting them.

Q6: (During my experience in EGR 191,) I will go/went above and beyond to earn a "A" in the class.

Q7: (During my experience in EGR 191,) I like to/took charge of my team.

Q8: (During my experience in EGR 191,) I like/liked being told exactly what I needed to do and worked well with a high level of structure.

Q9: As a team member (or During my experience in EGR 191), I work/worked well under pressure.

Q10: (During my experience in EGR 191,) I find/found conflict stressful and destructive.

Q11: (During my experience in EGR 191,) if a teammate is/was not doing his or her job, I will step/stepped in and complete/completed the task so that the work is/was done on time and to my standard.

The final survey included the following question.

Q12: Rate the effectiveness of the following strategies/tools on the success of your EGR 191 team. Select "very low", "low", "neutral", "high" or "very high".

- Gallup StrengthsFinder Inventory (i.e. learning about top strengths)

- Strategic team formation based on CATME TeamMaker

- Team Contract (i.e. definition of goals and commitments)

- Conflict Resolution Instruction (i.e. discussion on conflict prevention and resolution

- CATME Peer Evaluations

- Interpersonal rapport with teammates

- Project management (e.g. planning, setting goals, delegating tasks, etc.) 